\title{
IMPROVEMENT OF A ROTARY VANE PUMP FOR AN OCEAN WAVE POWER CONVERTER: PENDULOR
}

\author{
Tomiji WATABE*, \\ Hirotaka YOKOUCHI**, Hideo KONDO**, \\ Masaru INOYA*** and Mamoru KUDO*** \\ * Director of T-Wave Consulting Volunteer,5-23-3, Misono, Noboribetsu, 059-0036 Japan \\ ** Prof.s of Faculty of Engineering, Muroran Institute of Technology, \\ 27-1, Mizumoto, Muroran, 050-8585 Japan \\ *** Senior Engineers of Engineering Division, Narasaki Co. Ltd. \\ 135, tsukiji, Muroran, 051-0031 Japan
}

\begin{abstract}
Since the former vane pump had been far below a target (efficiency was $27 \sim 37 \%$ only) as reported at the $3^{\text {rd }}$ JHPS Yokohama, a revised pump was made to solve the problem and it proved $52 \%$ higher efficiency than the former one at indoor tests.

Prior to the revised pump, wear of the former pump parts were investigated after a 32 months sea operation. Adding the field test, the other data were taken through a half size model pump test.

Applying the data, the revised pump design was done. The Pendulor attached with the revised pump has proved so excellent power conversion that the plant efficiency was about $40 \sim 60 \%$ at sea operation.
\end{abstract}

\section{KEY WORDS}

Vane pump, design, ocean wave, Pendulor, experiment

\section{INTRODUCTION}

The authors invented a wave power converter named New Pendulor which consists of a pendulum and a large vane pump placed on the pendulum shaft as a part of it. The profile of the New Pendulor has realized a simple hard ware style of the system by accepting the pump. Fig. 1 shows the concept of the New Pendulor[1]. On the contrary of the style, there found a poor conversion efficiency in a 32 months sea operation. The main cause was by an unexpected oil leak occurred in the pump[2]

During the sea test, the New Pendulor proved an excellent survivability that means it has cleared one of the highest hurdles However, solving the oil leak was the urgent theme for the Pendulor

Two kinds of studies were done with the full size pump (tested at sea) and a half size model (prepared for the leak study). Then it was found that both designs of the pump case and the oil seal, had to be changed to reduce the leak loss

Applying the results of the studies, a revised pump was designed and made. The pump proved $52 \%$ higher efficiency at the indoor tests. Since Oct. 1998, it has been in a sea test run, in front of Muroran Harbor where the former one was tested. It seemed that the knowledge being grasped through the experience was very valuable to solve the problems of this case.

\section{FARTHER INVESTIGATION OF THE FORMER PUMP}

Fig. 2 shows the former vane pump. The pump shaft supports the pendulum (see Fig. 1) so that the pendular motion can be transmitted to the pump rotor directly to be altered into fluid power[3]. It proved that the design made the system to be more robust physically towards storms, nevertheless the pump efficiency was only $27 \sim 37 \%[2]$.

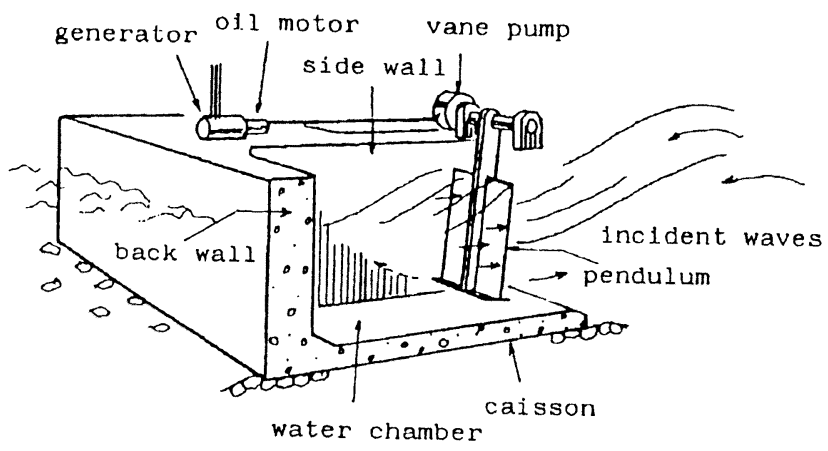

Fig. 1 The New Pendulor

In order to investigate the leak loss, the pump parts were inspected after the 32 months operation. As shown in Fig. 2, several parts were hurt, for example, some sliding portions: the rotor and the seal were scratched by abnormal contacts. All the seals(5) were broken so that the bearing(2) was corroded by sea water. The bearings(3)and (4) were also corroded nevertheless the seals(6) had functioned to protect the bearings from sea water.

It could be supposed as follows:

1) The earth connectors(1) which protects the bearings were damaged first by electric corrosion.

2) All the bearings(2), (3)and (4) were exposed in a corrosive atmosphere caused by electric current.

3) Corrosive wear of the bearings made an deviation of the shaft from the center axis so that sliding condition of the parts changed into hard contact and abrasive one.

4) The seals(5) were broken by irregular movement of the shaft, then sea water came to the bearing, after that the bearing was corroded more rapidly by the water. 
5) The straight seals were considered to oppose either side pressure so that they were liable to miss the initial leak flow whenever pressure changed over. Pressure delay was observed

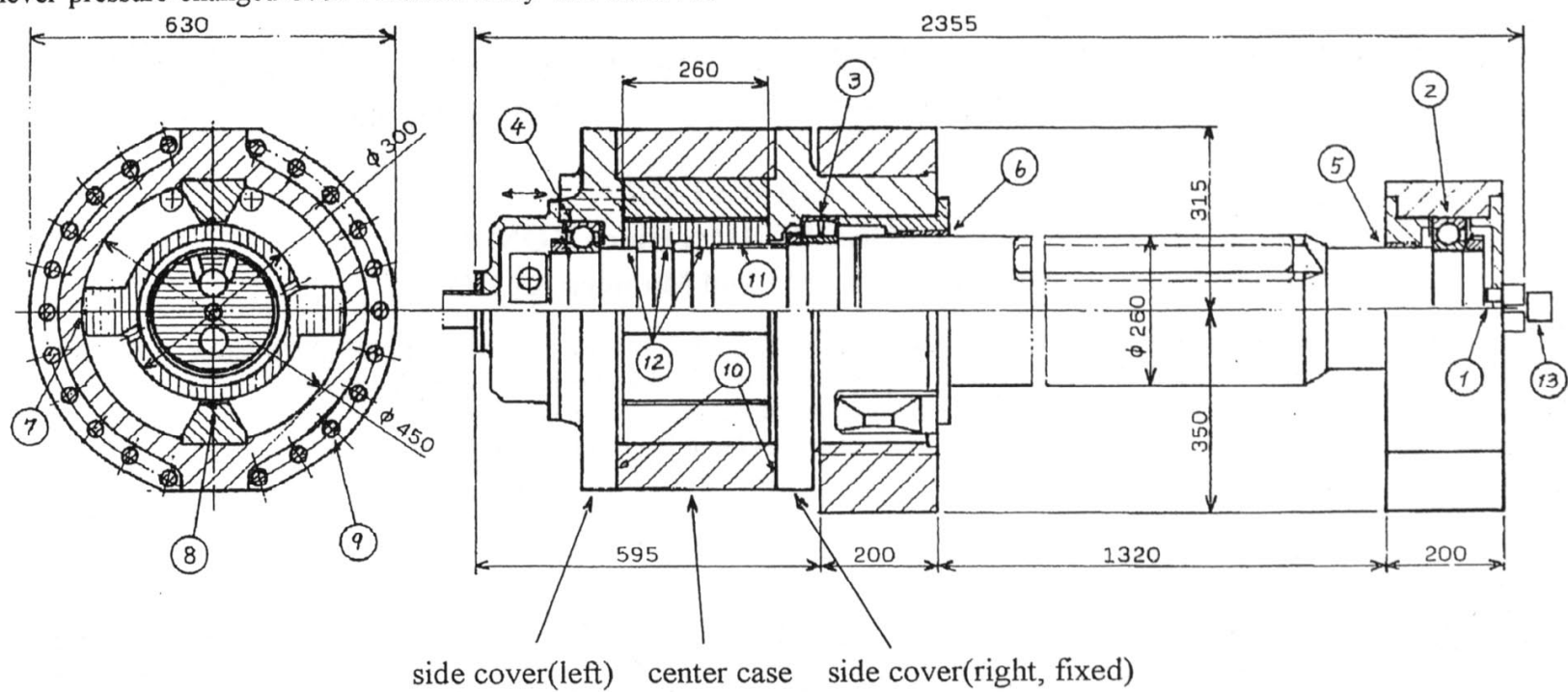

(1)broke the earth lines down, (2)erosion by electric current \& sea water (increased gap: 2.0mm), (3)electric erosion (increased gap: $0.2 \mathrm{~mm}$ ), (4)electric erosion (increased gap: $0.2 \mathrm{~mm}$ ), (5)broke all the seals down, (6)broke four seals down (out of five ones), (7)abrasive wear by metal contact (at the edge), (8)abrasive wear by metal contact (at the top), (9)loosened bolts (by excessive tension), (10)oil leak(through the saps appeared), (11)strong contact marks(on same parts of splines), (12)strong contact marks (on the shaft) and (13)broke the shaft of the rotary encoder down

Fig. 2 The former vane pump (resulted after 32 months sea operation)

From the investigation, these were concluded;

1) Protection of corrosion must be considered with the best precaution.

2) A couple of single straight seal should be used instead of the former type one.

\section{EXPERIMENTAL STUDY WITH A 1/2 SCALE MODEL}

Fig. 3 shows the model pump which was used for the seal study. Material of the seal was ductile iron. The model pump was so considered that a couple of single seal or a couple of double seal could be studied in a same condition. The leak flow passed into the next chambers or into the suction chamber, was measured individually. Inside of the pump was observed with a fiber scope to see the real leak phenomena. Torque efficiency was also measured.

There were three kinds of leakage in the pump;

1) The flow leaked across the seal, was observed both around the straight seal and the circular seal.

2) The flow leaked along the seal, was observed around only the circular seal.

3) The flow leaked through fine gaps, was found by the fiber scope observation. The gaps were bone due to elastic deform of the case as rising the oil pressure.

The straight seal was constructed with some seal elements so that there were in-avoidable passages wherever two elements met each other. The passages produced additional leak flow.

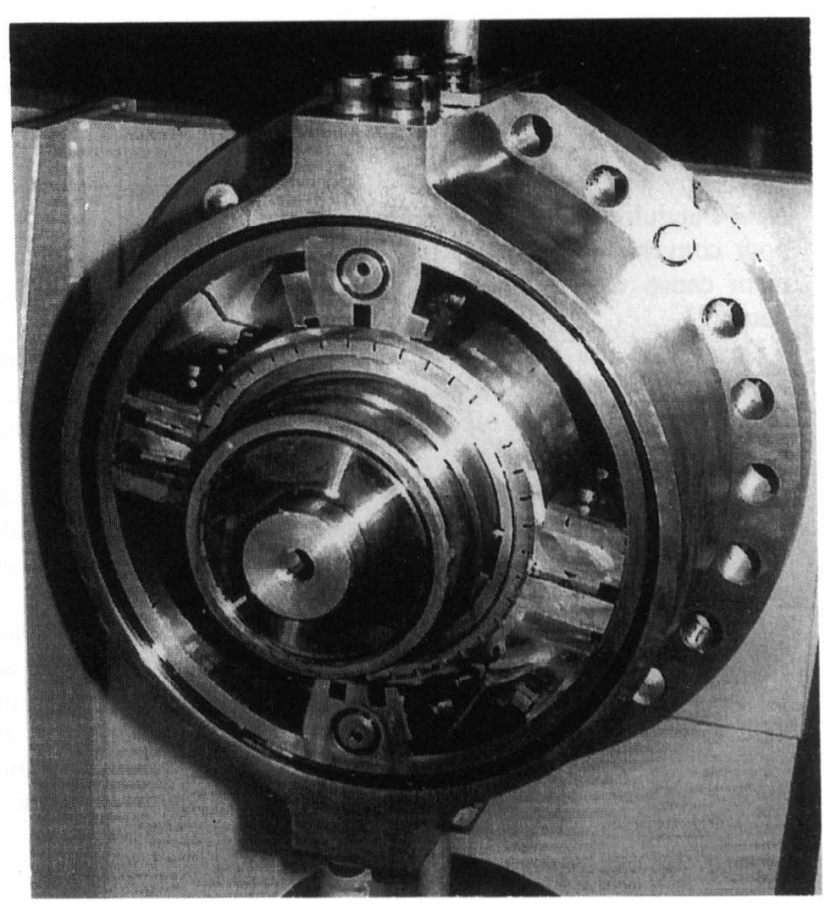

Fig. 3 The 1/2 scale model pump for the seal study 
Fig. 4 shows a straight seal with no passages, which was invented for free from the passages. Comparison test with the invented seal and the conventional one clarified that the influence of the passages was not so big comparing with the flow by the other passages explained next.

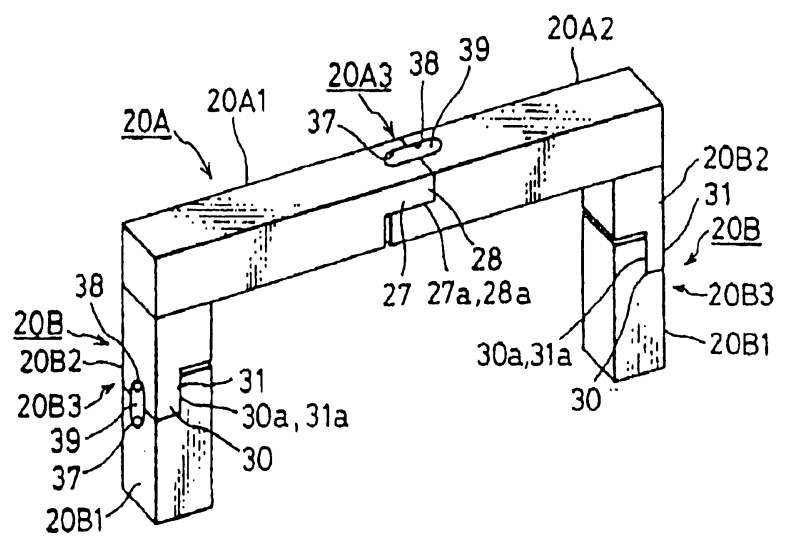

Fig. 4 The straight seal with no passages

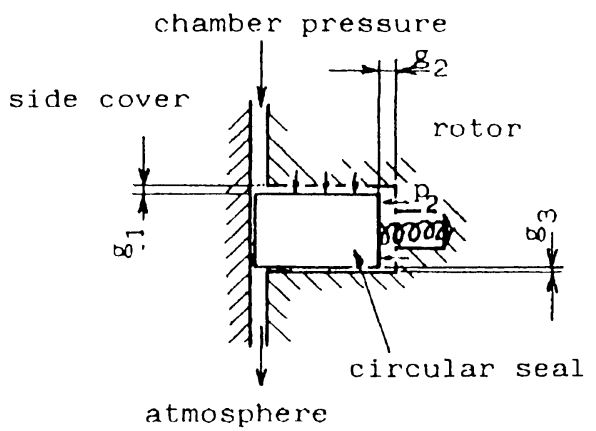

Fig. 5 Cross section of the circular seal
In order to avoid instability, the circular seal needs enough pressure $p_{2}$ behind it as illustrated in Fig. 5. It means the gaps $g_{l}$ and $g_{2}$ must be selected in an enough size. But the gaps allow plenty of leak flow passing through the gaps. The flow does not go across the seal but goes along the seal. For this reason, the gaps $g_{I}$ and $g_{2}$ cannot be large, the gap $g_{3}$ must be $g_{3}$ " $g_{I}$ and

$g_{3}$ « $g_{2}$.

Since the oil pressure grows in the one side chamber only, the pump case is deformed by it non-uniformly. As the result, circular-fitting portions would be released from tight contact, yielding any gap. Additional leak could appear like this. Similar additional leak was observed in the former pump (Fig. 2).

\section{REVISED DESIGN OF THE PUMP}

Referring the test results on the former pump, the revised one was designed. Fig. 6 shows the pump.

Since the displacement of the pump: $D_{p}=45.9 \mathrm{l} / \mathrm{rev}$. was determined by the equation derived from an linear theory[4], pump capacity has become slightly bigger than the suitable level. Due to the reason, pump pressure (max.) was reduced from $p=25 \mathrm{MPa}$ to $p=16 \mathrm{MPa}$. Accumulators and relief valves were re-adjusted to fit the pump pressure.

Design principle of the pump are shown next.

\section{Table 1 Design principle of the revised pump}

1) To follow the basic ideas of the former design: the simplicity and the robust mechanism.

2) To make the pump being completely free from corrosion.

3) Instead of the former one, a couple of single seals are provided for the either pressure use in order to improve stability and dynamic response of the seal.
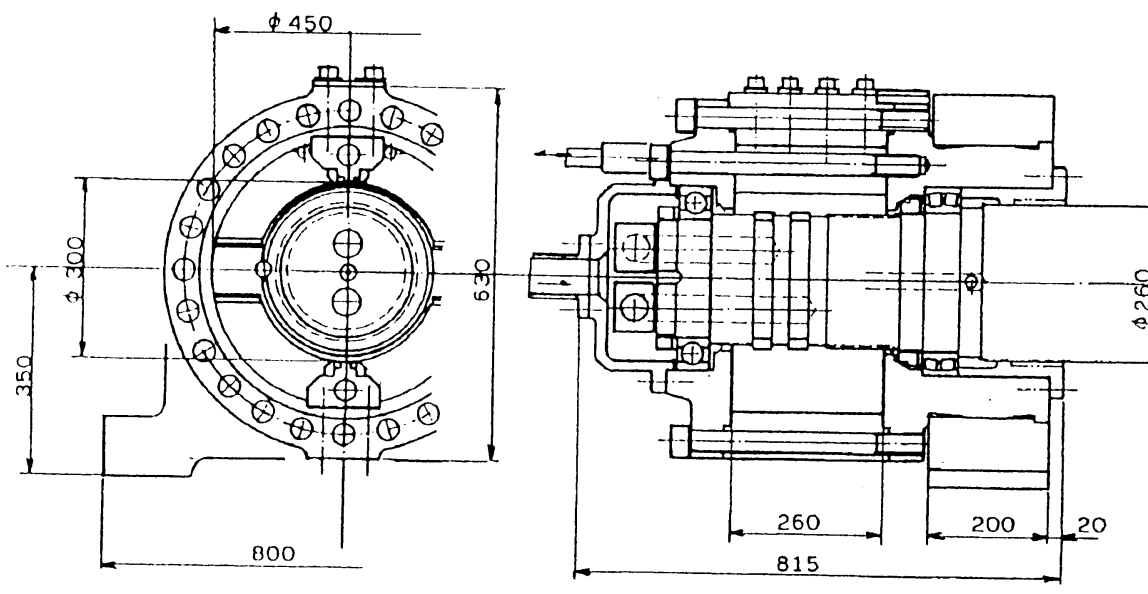

$D_{p}: 45.9$ 1/rev., No. of vanes: 2 , rotor size: $\phi 450 \times \phi 300 \times b 260$ swing angle: $\pm 50^{\circ}$, pressure: $16 \mathrm{MPa}$, output: $20 \mathrm{~kW} \max .($ at $2.0 \mathrm{l} / \mathrm{s}$ )

Fig. 6 The revised vane pump 
Comparing with Fig. 2, the pump shown Fig. 6 is considered to reduce the case deformation by enlarging the case thickness and four bolts more than Fig. 2, are used for fastening the case.

Due to shortage of the budget, the former rotor is reused though, some ideas for seal are applied on it. They are as follows:

1) All the straight seals consist of two single seals combination: a seal for the rightward pressure and another one for the leftward pressure.

2) The seals are set at a standby position pushed by springs so that there is no initial leak flow.

3) The seals can be placed steady in the channels by the shape even the springs always push them outward. This idea assists the pump assembly work to be done easily.

4) The circular seal is pushed by pressure led by passages which are prepared on the seal surface. Therefore, the seal keeps good stability. The seal is so designed that the pressure oil does not flow across the seal nor along the seal (patent pending).

The circular fittings of the case are provided in the zone being out of pressure. No leak flow is possible caused by the deform.

The earth connectors have bigger capacity for electric current to the earth with two carbon brushes.

In order to protect the bearings, the shaft surface is coated with ceramics and all the bearings are mounted on the layer to be insulated by it.

Watertight seals are provided on the shaft. Since the surface of the shaft should be kept fine, it is covered with stainless steel layer. Hard chromium plating is piled on the layer as well. For the better lubrication, grease grooves are provided among the seals.

\section{MANUFACTURING AND ITS INDOOR TESTS}

The parts were machined by Nagasawa Machine Co. Muroran and Narasaki Co. Muroran assembled and tested the pump on trial before it started the sea operation.

The pump was fixed on a basement and inside of it was filled with pressurized oil. Under that condition, internal leak flow and shaft moment were measured in relation with the oil pressure. Typical results are shown in Fig. 7 9.

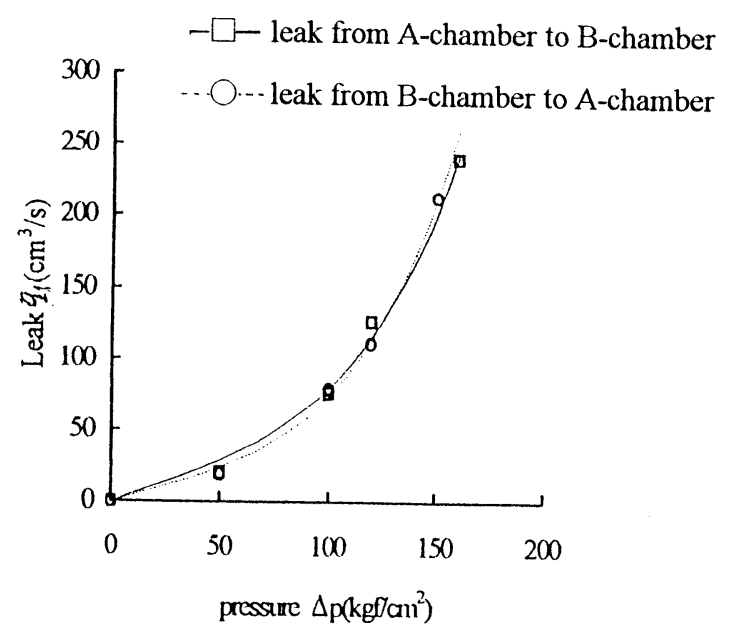

Fig. 7 Leak flow of the pump

Fig. 7 is the leak flow. The flow $q_{1}$ can be written in Eq.(1).
The second term shows a flow through a gap of which size is proportional to $\Delta p$.

$$
q_{1}=k_{p} \Delta p+k_{g} \Delta p^{4}
$$

where $k_{p}$ and $k_{g}$ : constant, $\Delta p$ : pressure difference between two chambers

Leak flow was $7.1 \mathrm{l} / \mathrm{m}$ at $\Delta p=12 \mathrm{MPa}$, so that the flow was equivalent to $6 \%$ delivery (rating $=120 \mathrm{l} / \mathrm{m}$, at $2.8 \mathrm{rpm}$ ) loss

Fig. 8 shows torque efficiency $\eta_{t}$ of the pump.

$\eta$, was $96 \%($ loss $=4 \%)$ at $\Delta p=12 \mathrm{MPa}$.

Therefore, pump efficiency $\eta \fallingdotseq 90 \%$ was clarified from the losses. It is $52 \%$ higher than the former one.

Fig. 9 shows a step response of the pump with pressure input. The time constant is about $0.2 \mathrm{sec}$.

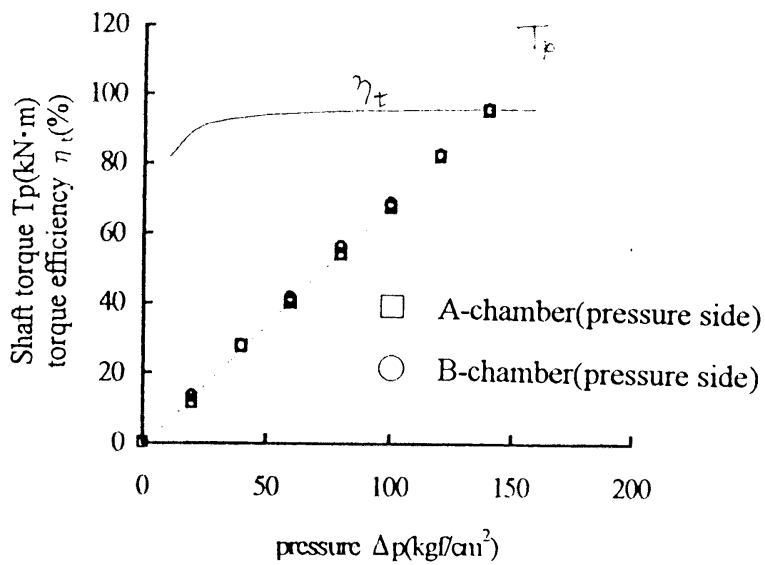

Fig. 8 Torque efficiency

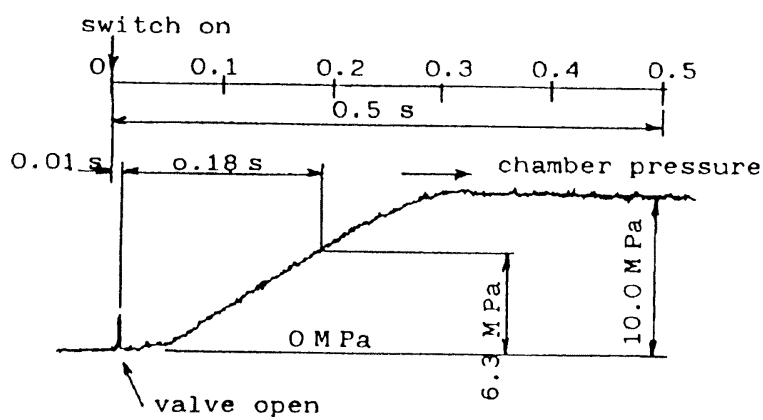

Fig. 9 Step response

\section{SEA OPERATION}

Since the pendulum assembly was like a pendulum alone, the setting work was very easy and safe using a 30-ton ship crane. The work was done under being open the water chamber to the incident waves.

The circuits of the sea test are shown in Fig. 10. Instead of a generator, there is a hydraulic pump (for the load to the input wave power). The pump load is adjusted by combination of the orifices for changing resistance in its delivery linc. In order to investigate the conversion characteristics, the resistance can be adjusted in 8 steps. Since the delivery pressure $p$ is shown, $p=k_{l}$ $n^{2}$, the power absorbed by the pump $W_{p 2}$ becomes, $W_{p 2}=k_{2} n^{3}$. The factor $k_{I}$ and $k_{2}$ are determined by combination of the orifices. 
The vane pump is driven by waves of which power $W_{w}$ can be known by measuring wave height $H_{1 / 3}$ and its period $T_{1 / 3}$. Input to the vane pump $W_{p}$ is calculated with pressure difference $\Delta p=p_{1}-p_{2}$ and angular displacement $\theta$ of the shaft when torque efficiency $\eta_{t}$ can be supposed. By ignoring pressure loss in the pipes, output of the pump can be known, as it is equal to input of the motor $W_{m}$. Since $W_{m}$ is proportional to $n_{m}\left(p_{3}+p_{4}\right)$, we can estimate pump efficiency $\eta=W_{m} / W_{p}$ with the data $p_{1}, p_{2}, p_{3}, p_{4}$, $\theta$ and $n_{m}$. This idea requires no expensive devices to test the pump in the severe atmosphere. But the results evaluate the pump efficiency a little bit lower than the real one

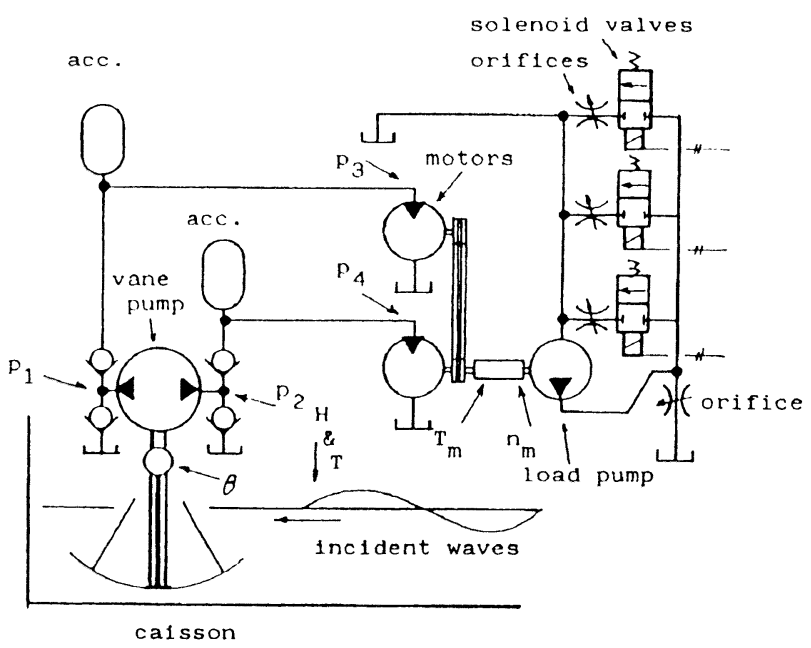

Fig. 10 The circuit of the sea test

Fig. 11 shows typical sea test results. They are indicated by the dots which were derived through a 20 minutes observation each including the live data. So, each the dot means an average value of 20 minutes. The pump efficiency $\eta$ is shown concerning with the wave period $T_{1 / 3}$. Since the Pendulor resonates to the waves of $T_{1 / 3}=4.2 \mathrm{~s}$, shorter waves than $4.2 \mathrm{~s}$ make lower the $1^{\text {st }}$ conversion $\eta_{1}$ as seen in the figure. Waves of the shorter period have the poorer energy, so that the shorter period affects worse to the conversion efficiency.

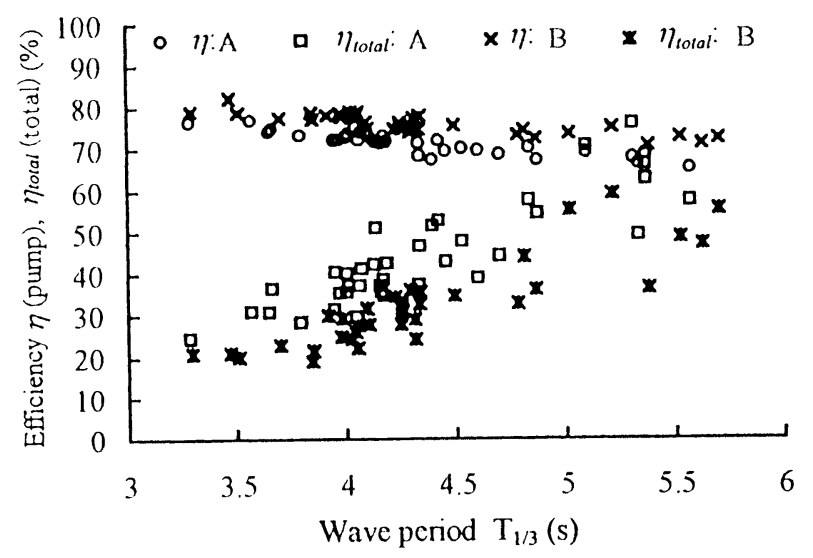

Fig. 11 Typical sea test results
The pump efficiency $\eta$ was around $65 \sim 80 \%$ when it was operated within $T_{1 / 3}=3.2 \sim 5.5 \mathrm{~s}$ including pressure loss by the pipeline.

The motor efficiency $\eta_{m}$ was above $80 \%$ when $T_{1 / 3} \geqq 4.5 \mathrm{~s}$.

The total efficiency $\eta_{\text {total }}=W_{g} / W_{w}$ was about $40 \sim 60 \%$ when $T_{1 / 3}$ $\geqq 4.5 \mathrm{~s}$. Here $W_{g}$ : output of the motors and $W_{w}$ : incident wave power. The level is extremely high in this field[5].

Fig. 12 shows the behavior of the pump in time domain. The angular displacement of the pump shaft $\theta$ has almost same pattern of the wave height $H$ (not shown)[6]. Although the pump delivers oil intermittently into the two lines, combination of the two makes the continuous motor rotation $n_{m}$. Since the wave power goes up and down quite wide range, the motor output also varies so wide that $3 \sim 23 \mathrm{~kW}(60 \sim 460 \%$ of the design rate $=5 \mathrm{~kW}$ ) is seen in the figure. The pump efficiency $\eta$ was $66 \%$, and the total efficiency $\eta_{\text {total }}$ was $57 \%$ at the moment.

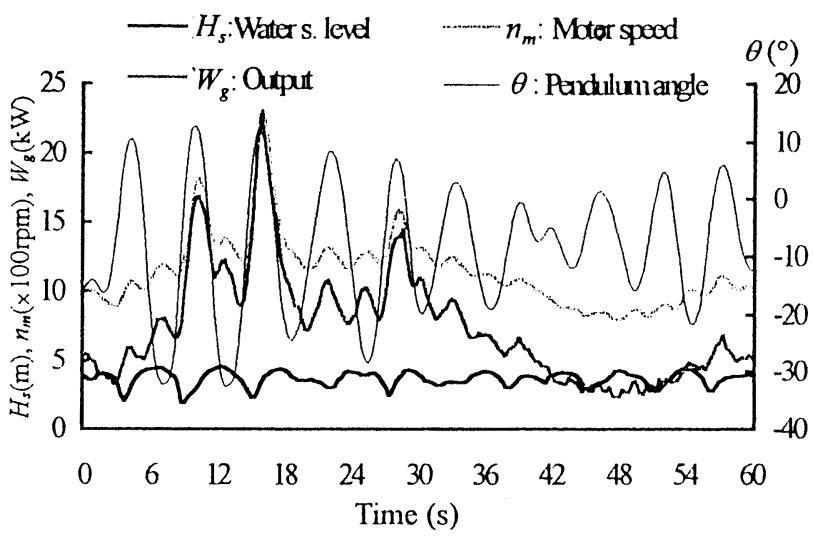

Fig. 12 Behavior of the pump in the sea test 


\section{CONCLUSIONS}

Through the studies, it can be concluded as follows:

1) The bearings must be protected from corrosion, especially electric corrosion. In order to make it sure, the earth connector must be durable towards not only chemical corrosion but also electric corrosion.

2) The seals studied here could show improved results in the leak test and the step response test.

3) The revised pump designed by applying the results proved $\eta=90 \%$ of the pump at the indoor test.

4) The pump efficiency at sea operation was $\eta \doteqdot 65 \sim 80 \%$ including a loss by pipe friction.

5) The Pendulor proved $\eta_{\text {total }} \doteqdot 40 \sim 60 \%$ at sea operation by attaching with this revised pump. The level is extremely high in the ocean wave study field.

This study has been done by a financial support of The Japanese Ministry of Education.

\section{REFERENCES}

1. Watabe, T. and et al, Pendular type ocean wave power converter, Japanese patent No.2539742, 1996.

2. Watabe, T. and et al, Studies on a large displacement pump for an ocean wave power converter, Proc. of the $3^{\text {rd }}$ JHPS Int. Symp. on Fluid Power Yokohama'96, pp.289-294

3. Watabe, T. and et al, Rotary vane pump, Japanese patent No.2573905, 1996.

4. Watabe, T., Manual of $15 \mathrm{~kW}$ Pendulor design, Design instruction of Pendulor, delivered privately, 1997, pp. 1 37 \& F1 F16.

5. Whittaker, T.J.T. et al, The Islay wave power project: an engineering perspective, (studies on a plant: output/input $=75 \mathrm{~kW} / 500 \mathrm{~kW}$ ), Proc. Civ. Engrs Wat., Marit. \& Energy, 1997, pp. 189 201.

6. Osanai, S. et al, Feasibility tests of new pendular type wave energy converter apparatus, Proc. of $25^{\text {th }}$ Int. Coastal Eng. Conference, Vol. 4, pp. 4591 4600. 